University of Wollongong

Research Online

Faculty of Engineering and Information

Faculty of Engineering and Information

Sciences - Papers: Part A

Sciences

$1-1-2013$

\title{
Influence of formulated chemical cleaning reagents on the surface properties and separation efficiency of nanofiltration membranes
}

Alexander Simon

University of Wollongong, as198@uowmail.edu.au

William E. Price

University of Wollongong, wprice@uow.edu.au

Long D. Nghiem

University of Wollongong, longn@uow.edu.au

Follow this and additional works at: https://ro.uow.edu.au/eispapers

Part of the Engineering Commons, and the Science and Technology Studies Commons

Research Online is the open access institutional repository for the University of Wollongong. For further information contact the UOW Library: research-pubs@uow.edu.au 


\title{
Influence of formulated chemical cleaning reagents on the surface properties and separation efficiency of nanofiltration membranes
}

\begin{abstract}
This study investigated the impact of two caustic and one acidic cleaning formulations (namely MC11, $\mathrm{PC98}$, and $\mathrm{MC} 3$, respectively) on the properties and separation efficiency of three different nanofiltration (NF) membranes (namely NF270, NF90 and TFC-SR100). Overall, the impact of chemical cleaning on surface properties and rejection was membrane and cleaning reagent specific. It was driven mostly by conformational changes of the membrane polymeric active skin layer in response to an extreme caustic or acidic environment and to a certain extent by the adsorption of cleaning additives (e.g., surfactants and chelating reagents). The influence of chemical cleaning on the membrane properties and separation efficiency was most severe for the NF270 due to its loose and very thin active skin layer. Caustic cleaning using either the MC11 or PC98 formulations led to a significant increase in the permeability and a considerable decrease in the rejection of both inorganic salts and trace organic contaminants by the NF270 membrane. In contrast, acidic cleaning using the MC3 formulation caused a small decrease in the permeability of the NF270 membrane. The influence of chemical cleaning on the NF90 and TFC-SR100 membranes was much less significant, possibly because of their thicker and denser active skin layer. The results reported here demonstrated that the impact of chemical cleaning was not permanent and could be minimised by adapting an appropriate strategy involving caustic cleaning followed by acidic cleaning. FTIR analyses of the virgin and cleaned membranes showed no discernible impact of chemical cleaning on the bonding structure of all three membranes investigatedhere.
\end{abstract}

\section{Keywords}

nanofiltration, efficiency, separation, properties, surface, reagents, cleaning, membranes, chemical, influence, formulated

\author{
Disciplines \\ Engineering | Science and Technology Studies
}

\section{Publication Details}

Simon, A., Price, W. E. \& Nghiem, L. D. (2013). Influence of formulated chemical cleaning reagents on the surface properties and separation efficiency of nanofiltration membranes. Journal of Membrane Science, $432(\mathrm{~N} / \mathrm{A}), 73-82$. 


\section{INFLUENCE OF Formulated Chemical Cleaning REAgents ON THE Surface Properties and SeParation EfFiciency of NANOfiLtration Membranes}

\section{Revised manuscript submitted to}

\section{Journal of Membrane Science}

December 2012

Alexander Simon ${ }^{1}$, William E. Price ${ }^{2}$, Long D. Nghiem ${ }^{1, *}$

${ }^{1}$ School of Civil Mining and Environmental Engineering

The University of Wollongong, Wollongong, NSW 2522, Australia

${ }^{2}$ School of Chemistry

The University of Wollongong, Wollongong, NSW 2522, Australia

* Corresponding author: Long D. Nghiem, Email longn@uow.edu.au; Tel: +61 242214590 


\begin{abstract}
This study investigated the impact of two caustic and one acidic cleaning formulations (namely MC11, PC98, and MC3, respectively) on the properties and separation efficiency of three different nanofiltration (NF) membranes (namely NF270, NF90 and TFC-SR100). Overall, the impact of chemical cleaning on surface properties and rejection was membrane and cleaning reagent specific. It was driven mostly by conformation changes of the membrane polymeric active skin layer in response to an extreme caustic or acidic environment and to a certain extent by the adsorption of cleaning additives (e.g. surfactants and chelating reagents). The influence of chemical cleaning on the membrane properties and separation efficiency was most severe for the NF270 due to its loose and very thin active skin layer. Caustic cleaning using either the MC11 or PC98 formulations led to a significant increase in the permeability and a considerable decrease in the rejection of both inorganic salts and trace organic contaminants by the NF270 membrane. In contrast, acidic cleaning using the MC3 formulation caused a small decrease in the permeability of the NF270 membrane. The influence of chemical cleaning on the NF90 and TFC-SR100 membranes was much less significant, possibly because of their thicker and denser active skin layer. The results reported here demonstrated that the impact of chemical cleaning was not permanent and could be minimised by adapting an appropriate strategy involving caustic cleaning followed by acidic cleaning. FTIR analyses of the virgin and cleaned membranes showed no discernible impact of chemical cleaning on the bonding structure of all three membranes investigated here.
\end{abstract}

Keywords: Chemical cleaning, formulated cleaning reagents, nanofiltration, trace organic contaminants (TrOC). 


\section{Introduction}

In recent years, water reuse has been widely adopted by many countries in response to the increasing demand for water brought about by the growing population, urbanisation, diminishing and uncertain availability of freshwater resources. In fact, water reuse is often regarded as a cost effective and environmentally friendly option in comparison to seawater desalination or long-distance water transfers for regions experiencing regular and severe droughts and water scarcity $[1,2]$. Since the quality of reclaimed water for potable reuse is stringently regulated, nanofiltration (NF) or reverse osmosis (RO) treatment has become an increasingly common component of water reclamation processes. NF/RO membranes can effectively remove a wide range of contaminants including inorganic salts and trace organic contaminants (TrOC) [3-5].

Membrane fouling (which may be caused by the deposition of organic and colloidal matter as well as the precipitation of inorganic salts on the membrane surface) and the inevitable periodic chemical cleaning are considered major drawbacks of NF/RO filtration processes [6]. Both can reduce not only the economic viability of the system but also the separation efficiency of the membranes. Recent studies have shown that membrane fouling can alter the rejection of TrOC by pore restriction, cake-enhanced concentration polarisation and modifications in the membrane charge and hydrophobicity [7-10]. Similarly, it has been suggested that chemical cleaning can accelerate the membrane ageing and negatively impact the separation efficiency of NF/RO membranes [11-14]. Therefore, the degradation of the membrane over time due to chemical cleaning can only be minimised with appropriate and optimised cleaning procedures [6].

Chemical cleaning by caustic and acidic cleaning reagents have been reported to result in significant variations in the membrane charge, hydrophobicity, permeability and rejection [11, $12,14]$. Nevertheless, little is known about the mechanisms associated with such changes in the membrane performance. Modifications of the membrane performance are thought to be caused by the enhanced electrostatic repulsion between functional groups of the membrane polymeric matrix during the chemical cleaning process or by the interaction between the membrane polymeric layer and the cleaning reagents. Consequently, when exposed to a strong caustic or acidic cleaning solution, the membrane porosity can either increase or decrease, respectively [14]. In fact, caustic cleaning has been reported to result in over $100 \%$ flux recovery [14-18]. Moreover, cleaning efficiency and the membrane permeability have been reported to increase significantly when surfactants and/or metal chelaters are used 
simultaneously with the caustic cleaning solution [15, 17, 19]. Liikanen et al. [15] suggested that at high $\mathrm{pH}$, metal chelaters such as ethylenediaminetetraacetic acid (EDTA) could complex with some membrane constitutes, rendering the membrane polymer even more open. Despite the need to understand the impact of formulated chemical cleaning on TrOC removal by NF/RO membranes, little information is currently available in the literature [20].

In practice, the composition of the fouling layer is often very complex. As a result, multiple chemical cleaning mechanisms are usually deployed to mitigate membrane fouling. Enhanced cleaning results can be achieved by combining several cleaning reagents either simultaneously or sequentially [21]. For example, the cleaning efficiency of the chelating reagent EDTA was reported to be most effective at above $\mathrm{pH} 10.3$, because all carboxylic functional groups of EDTA are fully deprotonated [19].

This study aims to investigate the impact of one acidic and two caustic cleaning formulations on the separation of two TrOC namely carbamazepine and sulfamethoxazole by three different NF membranes. The selected cleaning reagents are commercially available and the selected TrOC were widely detected in the secondary treated effluent. Changes in the membrane properties such as zeta potential, hydrophobicity, permeability and the chemical bonding structure were linked to the variations in the salts and $\mathrm{TrOC}$ rejection.

\section{Materials and methods}

\subsection{Chemicals and reagents}

Three commercially available formulated chemical cleaning reagents - namely MC11, MC3 and PC98 - were used for the membrane cleaning experiments. The MC11 and PC98 are caustic cleaning formulations while the MC3 is an acidic cleaning formulation. The exact chemistries of the three cleaning formulations are proprietary information of the manufacturers. The MC11 and MC3 were delivered in powder form and cleaning solutions were prepared following the manufacturer recommendations, resulting in clear liquids with a $\mathrm{pH}$ of 11.2 and 3 at $20 \pm 1{ }^{\circ} \mathrm{C}$, respectively. According to the manufacturer, MC11 is a blend of detergent builders, $\mathrm{pH}$ buffer and chelating reagents including ethylenediaminetetraacetic acid (EDTA), sodium tripolyphosphate (SDP) and trisodium phosphate (TSP). MC3 is an acidic cleaning reagent consisting of organic acids, detergent builders and the chelating reagent SDP. The PC98 was delivered in a liquid form. The recommended cleaning 
concentration of PC98 was $4 \%$ (wt/wt), resulting in a pH of 11 at $20 \pm 1{ }^{\circ} \mathrm{C}$. According to the manufacturer, PC98 contains surfactants and the chelating reagent EDTA.

Analytical grade sulfamethoxazole and carbamazepine were purchased from Sigma-Aldrich (Castle Hill, New South Wales, Australia). Sulfamethoxazole has a $\mathrm{pK}_{\mathrm{a}}$ value of 5.8 and thus the compound can deprotonate and become a negatively charged species when the solution $\mathrm{pH}$ increases to above 5.8. By contrast, carbamazepine can only exist as a neutral species in the environmental $\mathrm{pH}$ range (i.e. $\mathrm{pH} 3$-10). Thus, these compounds were selected as model organic compounds to investigate the behaviour of negatively charged and neutral organic TrOC, respectively. The molecular weight of sulfamethoxazole is $253.3 \mathrm{~g} / \mathrm{mol}$ and that of carbamazepine is $236.3 \mathrm{~g} / \mathrm{mol}$. Both compounds are hydrophilic and are not expected to adsorb to the membrane polymeric matrix. A stock solution was prepared by diluting $1 \mathrm{~g} / \mathrm{L}$ of each compound in methanol. The stock solution was stored in a freezer at $-18{ }^{\circ} \mathrm{C}$ and used within one month. All other chemicals used in this study were also of analytical grade.

\subsection{Membranes}

Three thin-film composite NF membranes - namely NF270, NF90 (Dow FilmTec, Minneapolis, MN, USA) and TFC-SR100 (Koch membrane systems, Wilmington, Massachusetts, USA) - were used in this study. The NF270 and NF90 membranes both contain a very thin semi-aromatic piperazine based polyamide active skin layer on a thick and porous polysulphone support [5]. The polyamide active skin layer of the NF270 membrane is reported to be approximately $15-40 \mathrm{~nm}$ thick and that of the NF90 is slightly thicker [22]. No information about the polymeric composition of the active skin layer of the TFC-SR100 is available. Despite the low permeability of the TFC-SR100 membrane, the calculated average pore diameter is comparable to that of the NF270 (Table 1). It appears that the TFC-SR100 has a thick active skin layer and/or a lower number of pores per unit area of membrane than those of the NF270. The recommended operation and cleaning range differ slightly from one membrane to another (Table 1).

\section{[Table 1]}

\subsection{Filtration setup and experimental protocol}

A laboratory-scale cross-flow NF/RO filtration system was used in this study. A detailed description of this system is available elsewhere [13]. The membranes were compacted prior to each filtration experiment at 18 bar using Milli-Q water until the permeate flux reached a 
constant value. A feed solution containing $1 \mathrm{mM} \mathrm{CaCl}_{2}, 20 \mathrm{mM} \mathrm{NaCl}$ and $1 \mathrm{mM} \mathrm{NaHCO}$ was used to simulate the ionic composition of typical secondary treated effluent and similar compositions have been used elsewhere by other researchers [23, 24]. $750 \mu \mathrm{g} / \mathrm{L}$ of each TrOC was added in the feed solution in all filtration experiments. The concentration of TrOC used here is an order of magnitude higher than what can be found in secondary treated effluent [25], however, this is necessary to ensure accurate analysis of a large number of samples. The feed $\mathrm{pH}$ was adjusted using $\mathrm{NaOH}(1 \mathrm{M})$ to $\mathrm{pH} 10$ and then stepwise reduced to pH 4 using $\mathrm{HCl}(1 \mathrm{M})$. The NF/RO filtration system was stabilized for at least 1 hour at each $\mathrm{pH}$ and samples of feed and permeate were taken for conductivity and trace-contaminant analysis. Feed temperature and cross-flow velocity were kept constant during the filtration experiment at $20 \pm 1{ }^{\circ} \mathrm{C}$ and $23.6 \mathrm{~cm} / \mathrm{s}$, respectively. The permeate flux of all filtration experiments was set at $42 \mathrm{~L} / \mathrm{m}^{2} \mathrm{~h}$, which is similar to the nominal permeate flux of the three membranes selected for this study (Table 1).

\subsection{Cleaning simulation}

Chemical cleaning was simulated by soaking virgin membrane samples in the cleaning solutions at $35{ }^{\circ} \mathrm{C}$ for 18 hours. The temperature was controlled using a water bath on top of a platform mixer, which ensured an active transport of the cleaning reagents to the membrane surface. The membrane samples were subsequently removed from the cleaning solution and gently rinsed with a copious volume of Milli-Q water prior to surface analysis or filtration experiments. Milli-Q water was also used as a control cleaning solutions with some virgin membrane samples to ensure all samples were treated in an identical manner. This cleaning simulation represents one cleaning event for a severely fouled membrane as recommended by DOW Filmtec [26]. It can also represent a series of routine preventative chemical cleaning protocols of 1 hour either every 3 or 6 months over 4.5 years using MC3 or MC11, as suggested by the manufacturer of these chemical cleaning formulations [27].

The simulated chemical cleaning protocol used in this study differs from the common procedure used in full-scale applications, where chemical cleaning is conducted by a successive cycle of soaking, cleaning solution circulation, and flushing of the membrane module with clean water. In full-scale installations, only the top layer of the membrane is exposed to the cleaning solution and exposure of the membrane polymeric surface to chemical cleaning reagents may be hindered to some extent by the fouling layer. In addition, elevated cleaning temperatures and high cross-flow velocities can also be used to improve the 
cleaning efficiency in full-scale applications. Nevertheless, the simulated chemical cleaning procedure used here allows for the systematic determination of membrane ageing due to chemical cleaning and similar protocols have widely been used in the literature [11-14, 28, 29].

\subsection{Trace organics analysis}

Carbamazepine and sulfamethoxazole rejection was analysed with a Shimadzu HPLC system (Kyoto, Japan) equipped with a Discovery C18 column (with diameter, length and pore size of $4.6 \mathrm{~mm}, 300 \mathrm{~mm}$ and $5 \mu \mathrm{m}$, respectively). Ultraviolet absorption detection at a wavelength of $280 \mathrm{~nm}$ was used. Two mobile phases were premixed with HPLC grade acetonitrile (ACN) and aqueous $\mathrm{KH}_{2} \mathrm{PO}_{4}(25 \mathrm{mM})$ and denoted as Eluent $\mathrm{A}(80 \% \mathrm{ACN} / 20 \%$ buffer solution) and Eluent B (20\% ACN/80\% buffer solution). The flow rate was $1.0 \mathrm{~mL} / \mathrm{min}$ and the sample injection volume was $50 \mu \mathrm{L}$. The detection limit using these conditions was approximately $20 \mu \mathrm{g} / \mathrm{L}$ for sulfamethoxazole and carbamazepine [30]. The analysis was conducted immediately after each filtration experiment.

\subsection{Membrane characterization}

\subsubsection{Zeta potential}

The membrane zeta potential was measured using a SurPASS electrokinetic analyser (Anton Paar $\mathrm{GmbH}, \mathrm{Graz}$, Austria). Zeta potential was calculated from the streaming potential using the Fairbrother-Mastin approach. Analytical grade hydrochloric acid ( $\mathrm{HCl})$ and potassium hydroxide $(\mathrm{KOH})$ were used to adjust the $\mathrm{pH}$. All streaming potential measurements were performed in $1 \mathrm{mM} \mathrm{KCl}$, at 500 mbar and room temperature $\left(25 \pm 1{ }^{\circ} \mathrm{C}\right)$. Each measurement was conducted four times by repeatedly reversing the flow direction. The measurement error was less than $1 \mathrm{mV}$.

\subsubsection{Membrane permeability measurement}

A stainless steel bench scale dead-end filtration system was used to measure the membrane permeability [31]. The system consisted of a stirred membrane cell $\left(21.2 \mathrm{~cm}^{2}\right)$, which was connected to a stainless steel reservoir. Instrument grade air was used to pressurize the system and the permeate flow was measured using a digital balance (Model Mettler Toledo, Ohio, USA) connected to a personal computer. The membrane was initially compacted for 1 hour using Milli-Q water at 6 bar and permeability measurement was finally conducted at 5 bar and room temperature $\left(25 \pm 1^{\circ} \mathrm{C}\right)$. 


\subsubsection{Membrane hydrophobicity measurement}

Membrane hydrophobicity was measured by the standard sessile drop method using a RameHart Goniometer (Model 250, Rame-Hart, Netcong, NJ). The membranes were air dried prior to the measurement and Milli-Q water was used as the reference solvent. At least 5 droplets were applied to membrane samples and the contact angle was measured on both sides of the droplet.

\subsubsection{Surface chemistry}

Fourier transform infrared spectroscopy (FTIR) analysis was conducted using a Shimadzu IRAffinity-1 (Kyoto, Japan) to determine major functional groups of the membrane polymeric surface. The instrument was equipped with a diamond crystal. The measured spectrum was between $750 \mathrm{~cm}^{-1}$ and $1750 \mathrm{~cm}^{-1}$. Each scan was performed 10 times at a resolution of $1 \mathrm{~cm}^{-1}$.

\section{Results and discussion}

\subsection{Impact on membrane properties}

\subsubsection{Zeta potential}

The charge of all three membranes in their virgin condition becomes more negatively charged as the solution $\mathrm{pH}$ increases due to the deprotonation of the carboxylic and amino functional groups of the active skin layer (Figure 1). The isoelectric point of the NF270 membrane was at $\mathrm{pH} 3$ and that of the NF90 and TFC-SR100 membranes was at pH 4 (Figure 1). Below the isoelectric point, all three virgin membranes were slightly positively charged.

Changes in the membrane charge in response to chemical cleaning were minor and were membrane and reagent specific (Figure 1). Among all cleaning formulations investigated here, MC3 was the only one that led to a small increase in the negative charge of the NF270 membrane (Figure 1a). This is consistent with previous studies, where no significant impacts in the charge of the NF270 membrane due to $\mathrm{NaOH}$, citric acid, SDS and EDTA cleaning of various concentrations were reported [14]. In contrast to the NF270 membrane, chemical cleaning resulted in discernible changes in the surface charge of NF90 and TFC-SR100 membranes (Figure 1b-c). It appears that chemical cleaning can reduce the surface charge density of the NF90 at both low and high pH (Figure 1b). This implies that, after chemical cleaning, the NF90 membrane was no longer positively charged below pH 4 and was less negatively charged at above $\mathrm{pH}$ 8. Similar observations could be made after the TFC-SR100 
membrane was exposed to the PC98 cleaning reagent. On the other hand, the TFC-SR100 became slightly more negatively charged after chemical cleaning with the MC11 and MC3 cleaning reagents. These changes in the membrane surface charge are likely due to the adsorption of the active ingredients of the cleaning formulations to the membrane polymeric matrix. In addition, changes in membrane surface characteristics such as surface roughness and chemistry in response to chemical cleaning might also influence the streaming potential measurement of the membrane [32]. However, the exact underlying mechanisms remain unknown and are subject to further inquiry.

\section{[Figure 1]}

\subsubsection{Hydrophobicity}

Changes in the membrane surface hydrophobicity measured by contact angle due to chemical cleaning are presented in Figure 2. In their virgin condition, both the NF270 and TFC-SR100 were hydrophilic, while the NF90 was moderately hydrophobic. The hydrophobicity of the NF270 decreased significantly after chemical cleaning with either the PC98 or MC3 reagent (Figure 2a). A small increase in the hydrophobicity of the NF270 after chemical cleaning with the MC11 reagent could be observed, however, it is noteworthy here that the virgin NF270 was quite hydrophilic. On the other hand, the hydrophobicity of the NF90 decreased significantly after exposure to any of the three formulated cleaning reagents used in this study (Figure 2b). Among all membranes tested in this study, changes in the surface hydrophobicity of the TFC-SR100 membrane due to chemical cleaning were negligible (Figure 2c).

The surface hydrophilicity (or wettability) of polyamide membranes depends on surface properties (e.g. roughness, porosity, chemistry) and on water-associating chemical groups (e.g. carboxyl and amino groups). Consequently, the hydrophobicity of polyamide membranes could be related to the surface charge [33]. However, as discussed in section 3.1.1 above, the changes in the membrane surface charge in response to chemical cleaning were rather negligible. Thus, most of the changes in the membrane surface hydrophobicity reported here can be attributed to the adsorption of cleaning components, such as surfactants and metal chelating reagents of the cleaning formulations used in this study.

\section{[Figure 2]}




\subsubsection{Permeability}

The impact of formulated cleaning reagents on the membrane permeability is summarised in Figure 3. According to Freger et al. [22], the NF270 membrane has a very thin active skin layer of approximately $15-40 \mathrm{~nm}$ and thus the permeability of this membrane is most sensitive to chemical cleaning. Chemical cleaning using the two caustic cleaning formulations PC98 and MC11 resulted in a significant increase in the permeability of the NF270 membrane. A similar trend, although much less significant can also be observed with the TFC-SR100. On the other hand, the acidic cleaning reagent MC3 caused a small decrease and increase in the permeability of the NF270 and TFC-SR100 membrane, respectively. Overall, the impact of chemical cleaning on the permeability of the NF90 membrane appeared to be negligible. This is because the NF90 has a smaller average pore diameter and possibly a thicker active skin layer amongst the three membranes studied here. Results reported in Figure 3 are consistent with a previous study using analytical reagents (such as $\mathrm{NaOH}$, citric acid, SDS, and EDTA) to simulate chemical cleaning [14]. When exposing a polyamide membrane to a caustic or a very strong acidic solution, the membrane charge density increases negatively or positively, respectively. This causes the membrane polymeric matrix to open up and as a result, the permeability after caustic cleaning increases as shown in Figure 3. The adsorption of surfactants and chelating reagents to the membrane active skin layer in a caustic condition can further exacerbate the increase in permeability [15]. On the other hand, the slight flux decline of the NF270 due to MC3 cleaning is likely due to charge neutralisation in an acidic environment (Figure 3a) as suggested by a previous study [14]. It is noteworthy that the observed increase or decrease in the membrane hydrophobicity caused by chemical cleaning (section 3.1.2) could also result in a decrease or increase in membrane permeability, respectively [11]. However, in this study, it seems that changes in the membrane porosity induce a stronger impact on the membrane permeability than those by membrane hydrophobicity.

\section{[Figure 3]}

\subsubsection{Surface chemistry}

In this study, FTIR analyses were conducted on both virgin and chemically cleaned membranes (Figure 4). The most important peaks that can be found for polyamide membranes are shown in Table 2. It is noteworthy that the reported top-layer thickness of the NF270 membrane $(15-40 \mathrm{~nm})$ is somewhat thinner than the average penetration depth of the 
FTIR beam $(<1 \mu \mathrm{m})$ [22]. Therefore, the characteristic peak of polypiperazinamide at 1630 $\mathrm{cm}^{-1}$ was not found on the NF270 (Figure 4a). On the other hand, a piperazine-peak was found on the NF90, since the active top-layer of the NF90 is slightly thicker than that of the NF270 (Figure 4b). The FTIR spectrum of the TFC-SR100 is similar to those of the NF270, and also includes a polypiperazinamide peak at $1630 \mathrm{~cm}^{-1}$ (Figure 4c), which supports the hypothesis that the TFC-SR100 membrane features a rather thick active top-layer. In this study, the FTIR spectra of the virgin and chemically cleaned samples of all three membranes investigated show no discernible variations in the chemical bonding structure. This is consistent with a previous study, in which cleaning reagents (i.e. $\mathrm{NaOH}$, Citric acid, EDTA and SDS) at various temperatures had no impact on the bonding structure of the NF270 membrane [34]. On the other hand, Zhu and Nyström [35] reported a further aromatic peak at $1500 \mathrm{~cm}^{-1}$ after a polysulphone UF-membrane was fouled and subsequently chemically cleaned with $\mathrm{NaOH}$. They proposed that $\mathrm{NaOH}$ could absorb the aromatic ether or hydrolyse the bond in para-position of the ether connection [35]. The difference between these reported results and the present study are likely due to the different cleaning protocols. Moreover, the possible chemical reaction proposed by Zhu and Nyström [35] are only applicable to polysulphone membranes rather than those investigated in this study (which are polyamide). The results shown here suggest that chemical cleaning at the manufacturer's recommended cleaning strength and at a cleaning temperature of $35^{\circ} \mathrm{C}$ do not result in any permanent changes in the bonding structure of polyamide membranes.

\section{[Figure 4]}

\subsection{Impact on rejection}

\subsubsection{Conductivity rejection}

The separation of salts by an NF membrane can be governed by both size exclusion and electrostatic interaction. The latter is strongly influenced by the membrane surface charge. Because the membrane zeta potential varied substantially as a function of the solution $\mathrm{pH}$ (Figure 1), salt rejection (measured by conductivity) by the virgin NF270, NF90 and TFCSR100 membranes also varied as a function of the feed solution $\mathrm{pH}$. The feed solution $\mathrm{pH}$ had a significant impact on the conductivity rejection by both the NF270 and TFC-SR100 membranes (Figure 5a and c), since they both have a relatively larger average pore size (Table 1). On the other hand, the impact of feed solution $\mathrm{pH}$ on the conductivity rejection by the virgin NF90 was negligible (Figure 5b). This is because the NF90 membrane is a tight NF 
membrane (Table 1) and salt rejection by this membrane is governed mostly by size exclusion.

It is interesting to note the different conductivity rejection behaviour of the NF270 and TFCSR100 membranes in response to changes in the feed solution $\mathrm{pH}$. Conductivity rejection by $\mathrm{NF} 270$ decreased as the feed solution $\mathrm{pH}$ decreased from $\mathrm{pH} 10$ to $\mathrm{pH} 3.5$. In contrast, the conductivity rejection by the virgin TFC-SR100 membrane decreased slightly as the $\mathrm{pH}$ changed from $\mathrm{pH} 10$ to 8 , then increased considerably as the $\mathrm{pH}$ continued to decrease to $\mathrm{pH}$ 3.5. The reason for this different conductivity rejection behaviour between the two membranes is not fully known and subject of further investigations. However, it is noteworthy that the virgin TFC-SR100 membrane is positively charged at pH 4 (Figure 1). Charge interaction between the positively charged membrane surface and the cations could enhance the rejection of these cations and thus partially explain for the increased in conductivity rejection observed in Figure 5c.

\section{[Figure 5]}

Chemical cleaning using caustic formulated cleaning reagents had a significant and permanent impact on the rejection of conductivity by the NF270 membrane. This appeared to be more severe than that caused by a $\mathrm{NaOH}$ solution (at $\mathrm{pH} 11.5$ and 12 , which was slightly higher than the $\mathrm{pH}$ of the cleaning formulations investigated here) reported in a previous study [14]. In this previous study, the impact of surfactants and metal chelating reagents (i.e. SDS and EDTA) at neutral $\mathrm{pH}$ on the membrane separation efficiency was negligible. In the current study, it appears that the adsorption of cleaning additives (i.e. surfactants and chelating reagents) on the surface and/or pores can exacerbate the impact of caustic cleaning on the separation efficiency and thus lead to a dramatic increase in the salt transport by the NF270 membrane (Figure 5a). It is noteworthy that no discernible impact on conductivity rejection by NF90 and TFC-SR100 membranes after chemical cleaning could be observed with either the MC11 or PC98 (Figure 5b-c). In addition, and in contrast to the two caustic cleaning reagents MC11 and PC98, the acidic cleaning formulation MC3 had only a minor impact on the conductivity rejection of all three membranes used in this study.

Changes in conductivity rejection can be driven by changes in the membrane surface charge and/or membrane porosity. Chemical cleaning did not exert any substantial impact on the zeta potential of the NF270 membrane (Figure 1). Thus, the decrease in conductivity rejection of the NF270 membrane after caustic cleaning observed here could be attributed to an increase 
in the membrane porosity. This hypothesis is consistent with the significant increase in permeability of the NF270 membrane after caustic cleaning (Figure 3a). However, the pore opening mechanism due to caustic cleaning suggested here seems to depend on the thickness of the membrane skin layer. Once again, the NF270 membrane has a very thin polyamide skin layer while those of the NF90 and TFC-SR100 are considerably thicker. In fact, caustic cleaning also did not result in a significant increase in permeability of either the NF90 or TFC-SR100 membranes. In addition, the acidic cleaning formulation MC3 had also only a small impact on the permeability (Figure 3a) and thus, on the conductivity rejection by the NF270 (Figure 5a).

\subsubsection{TrOC rejection}

In this study, the impact of chemical cleaning on the rejection of neutral and ionisable TrOC was investigated using carbamazepine and sulfamethoxazole as the model compounds, respectively. Within the $\mathrm{pH}$ range of 4 to 10 examined here, carbamazepine is a neutral and a moderate hydrophobic compound (section 2.1). The feed solution $\mathrm{pH}$ affected slightly the carbamazepine rejection by the NF270 membrane (Figure 6a), however, not by the NF90 and TFC-SR100 membrane (Figure $6 \mathrm{~b}$ and c). Sulfamethoxazole is a hydrophilic compound with a $\mathrm{pK}_{\mathrm{a}}$ of 5.81 and therefore can speciate within the $\mathrm{pH}$ range studied here. At $\mathrm{pH}$ well above the $\mathrm{pK}_{\mathrm{a}}$, the compound is negatively charged and will be predominantly rejected via chargerepulsion by negatively charged membranes. At well below $\mathrm{pH} 5.81$, the sulfamethoxazole molecule is protonated and in a neutral form and size exclusion will be the predominant rejection mechanism. Therefore, and in comparison to carbamazepine, sulfamethoxazole rejection by virgin NF270 and TFC-SR100 membranes varies dramatically with the background $\mathrm{pH}$ (Figure $7 \mathrm{a}$ and $\mathrm{c}$ ). In contrast, no significant variation on sulfamethoxazole rejection due to variations of the feed $\mathrm{pH}$ on the tighter virgin NF90 membrane could be observed (Figure $7 b$ ).

\section{[Figure 6]}

\section{[Figure 7]}

The variations in carbamazepine rejection due to chemical cleaning were consistent with the change in permeability. Among all membranes investigated in this study, cleaning the NF270 with MC11 and PC98 decreased the rejection of carbamazepine due to significant pore opening effects (Figure 6a). Note that PC98 resulted in a slightly more significant decrease in the carbamazepine rejection than $\mathrm{MC} 11$, which can be explained by the different chemical 
compositions of these caustic cleaning reagents (i.e. chelating reagents and surfactants). On the other hand, charge neutralisation of the NF270 membrane due to MC3 cleaning increased slightly the steric hindrance of the membrane and thus, the carbamazepine rejection (Figure 6a). Again, the NF90 and TFC-SR100 membranes have likely a thicker active skin layer in comparison to the NF270 (section 2.2). Therefore, it is expected that chemical cleaning of the NF90 and TFC-SR100 membranes would have little impact on the carbamazepine rejection in this study (Figure 6b and c).

Caustic cleaning (i.e. MC11 and PC98) had a notable effect on the rejection of sulfamethoxazole by the NF270 membrane, particularly below $\mathrm{pH} 8$ (Figure 7a). As discussed above, at low $\mathrm{pH}$, sulfamethoxazole is neutral and thus size exclusion is the main rejection mechanism. Above $\mathrm{pH} 8$, the compound is predominantly negative charged and charge repulsion appears to be the dominant rejection mechanism. As a result, changes in the membrane porosity did not affect the sulfamethoxazole rejection by the NF270 membrane (Figure $7 \mathrm{a}$ ). The results reported here regarding the impact of caustic cleaning formulations on sulfamethoxazole rejection are consistent with previous studies by Simon et al. [14, 34]. Simon and co-workers reported no discernible effect of chemical cleaning on the sulfamethoxazole separation by the NF270 membrane above a filtration $\mathrm{pH}$ of 8 , by analytical $\mathrm{NaOH}$, citric acid, SDS, and EDTA at various concentrations and temperature of up to $50{ }^{\circ} \mathrm{C}$. No discernible variation in either the neutral or negatively charged sulfamethoxazole rejection by the NF90 and TFC-SR100 membranes due to chemical cleaning could be observed (Figure $7 b-c$ ). In good agreement with the rejection data for conductivity and carbamazepine, the acidic cleaning formulation MC3 showed the least impact on the rejection of sulfamethoxazole by all three membranes investigated here (Figure 7).

\subsection{Effects of chemical cleaning sequence}

Results from the previous sections suggest that caustic cleaning formulations can exert a considerable impact on the permeability and separation capacity of NF membranes, particularly those with a thin active skin layer such as the NF270. The increase in permeability and the decrease in conductivity and TrOC rejection after caustic cleaning observed in this study were most likely driven by confirmation changes of the polyamide active skin layer. These conformational changes of the polyamide active skin layer can be described by a simplified schematic diagram as shown in Figure 8 . When the membrane is 
exposed to a high $\mathrm{pH}$ cleaning solution, electrostatic interactions amongst the deprotonated (and thus negatively charged) carboxylic functional groups of the polyamide active skin layer resulted in the swelling of the membrane polymeric matrix. The swelling caused at a high $\mathrm{pH}$ cleaning condition leads to a significant enlargement of the membrane pore volume or porosity. When the membrane is returned to operation, exposing to a near neutral $\mathrm{pH}$ (i.e. $\mathrm{pH}$ 7) solution, functional groups at the membrane surface can be re-protonated and caustic cleaning only cause small or very minor changes in the zeta potential of the membrane surface as reported previously in section 3.1.1. However, the active skin layer immediately underneath the membrane surface can experience a hysteresis condition, similar as it was observed to happen due to elevated cleaning temperatures $[34,36]$. Due to this hysteresis effect, over a long time scale, the porosity of the membrane active skin layer decreases and returns to the normal value. In other words, a more open surface structure of the membrane, due to strong caustic cleaning, remains in place in a steady state condition, resulting in a higher membrane permeability and solute passage as shown in the previous sections. On the other hand, because the polyamide membranes have an isoelectric point at approximately $\mathrm{pH}$ 3 , acidic cleaning at this $\mathrm{pH}$ can result in charge neutralisation. Therefore, the impact of acidic cleaning on both permeability and solute separation efficiency is rather insignificant (sections 3.1.3 and 3.2). However, it is hypothesized that acidic cleaning immediately after caustic cleaning can help to remove the above mentioned hysteresis effect. To evaluate this hypothesis, a short acidic cleaning procedure of either 2 or 4 hours was performed using the acidic MC3 cleaning formulation immediately after caustic cleaning using the MC11 formulation (Figures 9 and 10). As discussed above, cleaning the NF270 for 18 hours with MC11 increased the permeability, salt and TrOC passage. Subsequent acidic cleaning with MC3 for 2 hours fully recovered the permeability to the value obtained with a virgin membrane sample, as shown in Figure 9. The rejection of conductivity, carbamazepine and sulfamethoxazole was also substantially restored (Figure 10). When the acidic cleaning duration with MC3 was increased to 4 hours, the rejection of both conductivity and TrOC were fully recovered (Figure 10). The results reported here confirm that the sequence of caustic following by acidic cleaning can be used to minimise the impact of chemical cleaning on the performance of polyamide NF membranes.

\section{[Figure 8]}

\section{[Figure 9]}

[Figure 10] 


\section{Conclusion}

The impact of chemical cleaning on surface properties and permeability of an NF membrane as well as its conductivity and TrOC rejection depends on the properties of both the membrane itself and the chemical cleaning formulation. The influence of chemical cleaning on the membrane properties and separation efficiency was most severe for NF270 because it is a loose NF membrane with a very thin active skin layer. Caustic cleaning using either the MC11 or PC98 formulations led to a significant increase in the permeability and a considerable decrease in the rejection of both conductivity and TrOC by the NF270 membrane. In contrast, acidic cleaning using the MC3 formulation caused a small decrease in the permeability of the NF270 membrane. Overall, the changes in permeate flux due to chemical cleaning were in good agreement with the changes in the rejection of both conductivity and TrOC. The influence of chemical cleaning on the NF90 and TFC-SR100 membranes was much less significant, possibly because of their thicker active skin layer. Changes in membrane surface charge and hydrophobicity caused by chemical cleaning formulations observed in this study were attributed to the adsorption of cleaning additives (i.e. surfactants and chelating reagents) to the membrane polymer. It is probable that the impact of chemical cleaning on permeability and separation efficiency was driven mostly by conformation changes of the polymeric matrix of the membrane active skin layer in response to an extreme caustic or acidic environment. Chemical cleaning did not appear to cause any significant permanent and chemical damage to the membrane. FTIR analyses of the virgin and chemically cleaned membranes showed no discernible impact of chemical cleaning on the bonding structure of all three membranes. The negative impact caused by caustic cleaning was fully reversed by a subsequent acidic cleaning procedure. Based on the results reported here, a chemical cleaning sequence of caustic followed by acidic is recommended to minimise the adverse impact of chemical cleaning on the performance of NF membranes.

\section{Acknowledgements}

This study was supported by the Australian Research Council Discovery Project DP0985389.

\section{References}

[1] M.A. Shannon, P.W. Bohn, M. Elimelech, J.G. Georgiadis, B.J. Marinas, A.M. Mayes, Science and technology for water purification in the coming decades, Nature 452 (2008) 301310 . 
[2] T. Wintgens, T. Melin, A. Schäfer, S. Khan, M. Muston, D. Bixio, et al., The role of membrane processes in municipal wastewater reclamation and reuse, Desalination 178 (2005) $1-11$.

[3] C. Bellona, J.E. Drewes, P. Xu, G. Amy, Factors affecting the rejection of organic solutes during NF/RO treatment - A literature review, Water Res. 38 (2004) 2795-2809.

[4] A. Verliefde, E. Cornelissen, G. Amy, B. Van der Bruggen, H. van Dijk, Priority organic micropollutants in water sources in Flanders and the Netherlands and assessment of removal possibilities with nanofiltration, Environ. Pollut. 146 (2007) 281-289.

[5] L.D. Nghiem, A.I. Schäfer, M. Elimelech, Removal of Natural Hormones by Nanofiltration Membranes: Measurement, Modeling, and Mechanisms, Environ. Sci. Technol. 38 (2004) 1888-1896.

[6] B. Van der Bruggen, M. Mänttäri, M. Nyström, Drawbacks of applying nanofiltration and how to avoid them: A review, Sep. Purif. Technol. 63 (2008) 251-263.

[7] H.Y. Ng, M. Elimelech, Influence of colloidal fouling on rejection of trace organic contaminants by reverse osmosis, J. Membr. Sci. 244 (2004) 215-226.

[8] L.D. Nghiem, S. Hawkes, Effects of membrane fouling on the nanofiltration of pharmaceutically active compounds ( $\mathrm{PhACs}$ ): Mechanisms and role of membrane pore size, Sep. Purif. Technol. 57 (2007) 176-184.

[9] L.D. Nghiem, S. Hawkes, Effects of membrane fouling on the nanofiltration of trace organic contaminants, Desalination 236 (2009) 273-281.

[10] A.R.D. Verliefde, E.R. Cornelissen, S.G.J. Heijman, I. Petrinic, T. Luxbacher, G.L. Amy, et al., Influence of membrane fouling by (pretreated) surface water on rejection of pharmaceutically active compounds (PhACs) by nanofiltration membranes, J. Membr. Sci. 330 (2009) 90-103.

[11] A. Al-Amoudi, P. Williams, A.S. Al-Hobaib, R.W. Lovitt, Cleaning results of new and fouled nanofiltration membrane characterized by contact angle, updated DSPM, flux and salts rejection, Appl. Surf. Sci. 254 (2008) 3983-3992.

[12] A. Al-Amoudi, P. Williams, S. Mandale, R.W. Lovitt, Cleaning results of new and fouled nanofiltration membrane characterized by zeta potential and permeability, Sep. Purif. Technol. 54 (2007) 234-240.

[13] A. Simon, L.D. Nghiem, P. Le-Clech, S.J. Khan, J.E. Drewes, Effects of membrane degradation on the removal of pharmaceutically active compounds (PhACs) by NF/RO filtration processes, Journal of Membrane Science 340 (2009) 16-25.

[14] A. Simon, E.W. Price, L.D. Nghiem, Effects of chemical cleaning on the nanofiltration of pharmaceutically active compounds (PhACs) Sep. Purif. Technol. 88 (2012) 208-215.

[15] R. Liikanen, J. Yli-Kuivila, R. Laukkanen, Efficiency of various chemical cleanings for nanofiltration membrane fouled by conventionally-treated surface water, J. Membr. Sci. 195 (2002) 265-276.

[16] S.S. Madaeni, S. Samieirad, Chemical cleaning of reverse osmosis membrane fouled by wastewater, Desalination 257 (2010) 80-86.

[17] X. Li, J. Li, X. Fu, R. Wickramasinghe, J. Chen, Chemical cleaning of PS ultrafilters fouled by the fermentation broth of glutamic acid, Sep. Purif. Technol. 42 (2005) 181-187. 
[18] Q. Li, M. Elimelech, Organic fouling and chemical cleaning of nanofiltration membranes: Measurements and mechanisms, Environmental Science and Technology 38 (2004) 4683-4693.

[19] W.S. Ang, A. Tiraferri, K.L. Chen, M. Elimelech, Fouling and cleaning of RO membranes fouled by mixtures of organic foulants simulating wastewater effluent, J. Membr. Sci. 376 (2011) 196-206.

[20] N. Porcelli, S. Judd, Chemical cleaning of potable water membranes: A review, Sep. Purif. Technol. 71 (2010) 137-143.

[21] A. Al-Amoudi, R.W. Lovitt, Fouling strategies and the cleaning system of NF membranes and factors affecting cleaning efficiency, J. Membr. Sci. 303 (2007) 4-28.

[22] V. Freger, J. Gilron, S. Belfer, TFC polyamide membranes modified by grafting of hydrophilic polymers: an FT-IR/AFM/TEM study, J. Membr. Sci. 209 (2002) 283-292.

[23] A.R.D. Verliefde, E.R. Cornelissen, S.G.J. Heijman, J.Q.J.C. Verberk, G.L. Amy, B. Van der Bruggen, et al., The role of electrostatic interactions on the rejection of organic solutes in aqueous solutions with nanofiltration, J. Membr. Sci. 322 (2008) 52-66.

[24] S. Lee, J. Cho, M. Elimelech, Influence of colloidal fouling and feed water recovery on salt rejection of RO and NF membranes, Desalination 160 (2004) 1-12.

[25] T. Heberer, Tracking persistent pharmaceutical residues from municipal sewage to drinking water, J. Hydrol. 266 (2002) 175-189.

[26] Dow Chemicals, Cleaning Steps, (2012) available from http://www.dowwaterandprocess.com/support training/literature manuals/filmtec manual.ht $\underline{\mathrm{m}}$.

[27] Floclean MC11, product sheet, (2012) available from http://www.kebansu.com/media/data/013-2-FLOCLEAN-MC11-10-2011.pdf.

[28] G. Kang, C. Gao, W. Chen, X. Jie, Y. Cao, Q. Yuan, Study on hypochlorite degradation of aromatic polyamide reverse osmosis membrane, J. Membr. Sci. 300 (2007) 165-171.

[29] A. Ettori, E. Gaudichet-Maurin, J.-C. Schrotter, P. Aimar, C. Causserand, Permeability and chemical analysis of aromatic polyamide based membranes exposed to sodium hypochlorite, J. Membr. Sci. 375 (2011) 220-230.

[30] D. Vogel, A. Simon, A.A. Alturki, B. Bilitewski, W.E. Price, L.D. Nghiem, Effects of fouling and scaling on the retention of trace organic contaminants by a nanofiltration membrane: the role of cake-enhanced concentration polarisation, Sep. Purif. Technol. 73 (2010) 256-263.

[31] T. Mariam, L.D. Nghiem, Landfill leachate treatment using hybrid coagulationnanofiltration processes, Desalination 250 (2010) 677-681.

[32] C. Schnitzer, S. Ripperger, Influence of Surface Roughness on Streaming Potential Method, Chemical Engineering \& Technology 31 (2008) 1696-1700.

[33] M. Mänttäri, A. Pihlajamäki, M. Nyström, Effect of $\mathrm{pH}$ on hydrophilicity and charge and their effect on the filtration efficiency of NF membranes at different $\mathrm{pH}$, J. Membr. Sci. 280 (2006) 311-320.

[34] A. Simon, W.E. Price, L.D. Nghiem, Impact of chemical cleaning on the nanofiltration of pharmaceutically active compounds (PhACs): The role of cleaning temperature, J. Taiwan Inst. Chem. E. (submitted) (2013). 
[35] H. Zhu, M. Nyström, Cleaning results characterized by flux, streaming potential and FTIR measurements, Colloid. Surface. A. 138 (1998) 309-321.

[36] M. Mänttäri, A. Pihlajamäki, E. Kaipainen, M. Nyström, Effect of temperature and membrane pre-treatment by pressure on the filtration properties of nanofiltration membranes, Desalination 145 (2002) 81-86. 


\section{List of captions}

Figure 1: Zeta potential of the NF270, NF90 and TFC-SR100 membranes before and after being exposed to the cleaning formulations MC11 (pH 11.2), MC3 (pH 3) and PC98 (pH 11) for 18 hours at $35{ }^{\circ} \mathrm{C}$. The measurement was conducted in $1 \mathrm{mM} \mathrm{KCl}$ at $20 \pm 1{ }^{\circ} \mathrm{C}$. Error bars show the standard deviation of repetitive measurements of three different membrane samples.

Figure 2: Hydrophobicity of the NF270, NF90 and TFC-SR100 membranes before and after being exposed to the cleaning formulations MC11 (pH 11.2), MC3 (pH 3) and PC98 (pH 11) for 18 hours at $35^{\circ} \mathrm{C}$. Error bars show the standard deviation of five repetitive measurements.

Figure 3: Measured permeability $\left(\mathrm{L} / \mathrm{m}^{2} \mathrm{~h}\right.$ bar) of the NF270, NF90 and TFC-SR100 membranes before and after being exposed to the cleaning formulations MC11 ( $\mathrm{pH} 11.2$ ), MC3 (pH 3) and PC98 (pH 11) for 18 hours at $35^{\circ} \mathrm{C}$. The measurement was conducted with Milli-Q water at 5 bar and $20 \pm 1{ }^{\circ} \mathrm{C}$. Error bar shows the standard deviation of three repetitive measurements.

Figure 4: Measured ATR-FTIR spectra of the NF270, NF90 and TFC-SR100 membranes before and after being exposed to the cleaning formulations MC11 (pH 11.2), MC3 (pH 3) and PC98 (pH 11) for 18 hours at $35^{\circ} \mathrm{C}$. The resolution was $1 \mathrm{~cm}^{-1}$.

Figure 5: Conductivity rejection by the NF270, NF90 and TFC-SR100 membranes before and after being exposed to the cleaning formulations MC11 (pH 11.2), MC3 (pH 3) and PC98 (pH 11) for 18 hours at $35{ }^{\circ} \mathrm{C}$. The feed solution contained $1 \mathrm{mM} \mathrm{CaCl}_{2}, 20 \mathrm{mM} \mathrm{NaCl}$ and 1 $\mathrm{mM} \mathrm{NaHCO}$. Cross-flow velocity, permeate flow and temperature were $23.6 \mathrm{~cm} / \mathrm{s}, 42 \mathrm{~L} / \mathrm{m}^{2}$ $\mathrm{h}$ and $20^{\circ} \mathrm{C}$, respectively. Error bars show the standard deviation of three repetitive measurements.

Figure 6: Carbamazepine rejection by the NF270, NF90 and TFC-SR100 membranes before and after being exposed to the cleaning formulations MC11 (pH 11.2), MC3 (pH 3) and PC98 (pH 11) for 18 hours at $35{ }^{\circ} \mathrm{C}$. Filtration conditions were as in Figure 5. Error bars show standard deviation of three repetitive measurements.

Figure 7: Sulfamethoxazole rejection by the NF270, NF90 and TFC-SR100 membranes before and after being exposed to the cleaning formulations MC11 (pH 11.2), MC3 (pH 3) and PC98 (pH 11) for 18 hours at $35^{\circ} \mathrm{C}$. Filtration conditions were as in Figure 5. Error bars show the standard deviation of three repetitive measurements. 
Figure 8: Schematic drawing of a membrane top layer as a function of the membrane charge (i.e. background $\mathrm{pH}$ ).

Figure 9: Measured permeability ( $\mathrm{L} / \mathrm{m}^{2} \mathrm{~h}$ bar) of the NF270 membrane before and after being exposed to the cleaning formulation MC11 ( $\mathrm{pH}$ 11.2) for 18 hours at $35{ }^{\circ} \mathrm{C}$ and then being subsequently recovered with MC3 ( $\mathrm{pH} \mathrm{3)}$ for 2 and 4 hours. The measurement conditions were as in Figure 5. Error bars show the standard deviation of three repetitive measurements.

Figure 10: Rejection of conductivity, carbamazepine and sulfamethoxazole by the NF270 membrane before and after being exposed to the cleaning formulation MC11 (pH 11.2) for 18 hours at $35{ }^{\circ} \mathrm{C}$ and then being subsequently recovered with MC3 (pH 3) for 2 and 4 hours. Filtration conditions were as in Figure 5. Error bars show the standard deviation of three repetitive measurements. 
Table 1: Properties of selected nanofiltration membranes

\begin{tabular}{|c|c|c|c|c|c|c|c|}
\hline Membrane & $\begin{array}{l}\text { Permeability } \\
\left(\mathrm{L} / \mathrm{m}^{2} \mathrm{~h} \text { bar }\right)^{\mathrm{a}}\end{array}$ & $\begin{array}{c}\text { Nominal } \\
\text { permeate flux } \\
\left(\mathrm{L} / \mathrm{m}^{2} \mathrm{~h}\right)^{\mathrm{a}}\end{array}$ & $\begin{array}{l}\text { Average } \\
\text { pore } \\
\text { diameter } \\
(\mathrm{nm})\end{array}$ & $\begin{array}{l}\text { Operating } \\
\text { pH range }{ }^{a}\end{array}$ & $\begin{array}{c}\text { Cleaning } \\
\mathrm{pH} \\
\text { range }^{\text {a }}\end{array}$ & $\begin{array}{c}\text { Max } \\
\text { operating } \\
\text { temperature } \\
\left({ }^{\circ} \mathrm{C}\right) \\
\end{array}$ & $\begin{array}{c}\text { Max } \\
\text { cleaning } \\
\text { temperature }{ }^{\mathrm{a}} \\
\left({ }^{\circ} \mathrm{C}\right)\end{array}$ \\
\hline NF270 & 11.13 & 52 & $\begin{array}{c}0.84 \\
\pm \\
0.05^{b}\end{array}$ & $3-10$ & $1-12$ & 45 & 35 \\
\hline NF90 & 6.26 & 32 & $\begin{array}{c}0.64 \\
\pm \\
0.01^{\mathrm{b}}\end{array}$ & $2-12$ & $1-12$ & 45 & 35 \\
\hline $\begin{array}{l}\text { TFC- } \\
\text { SR100 }\end{array}$ & 5.73 & 26.3 & $\begin{array}{c}0.80 \\
\pm \\
0.08^{c}\end{array}$ & $4-10$ & $1.7-11.5$ & 50 & 45 \\
\hline
\end{tabular}

${ }^{\mathrm{a}}$ According to the manufacturers

${ }^{\mathrm{b}}$ Data from [28]

${ }^{\mathrm{C}}$ Calculated using the method previously reported by Nghiem et al. [28]

Table 2: Peak assignment of the FTIR spectra

\begin{tabular}{|l|c|c|c|}
\hline $\begin{array}{l}\text { Wavenumber } \\
\left(\mathrm{cm}^{-1}\right)\end{array}$ & Peak assignment & Polymer & Reference \\
\hline 1663 & $\begin{array}{c}\text { C=O and/or C-N stretching and/or C-C-N } \\
\text { deformation vibration (amide l) }\end{array}$ & PA & {$[32,33]$} \\
\hline 1640 & Polypiperazinamide (amide 1) & Polypiperazinamide & {$[32]$} \\
\hline $\begin{array}{l}1586 \\
\text { and } 1488\end{array}$ & Aromatic in-plane bend stretching vibration & PSf & {$[29,32,33]$} \\
\hline 1544 & C-N stretching (amide ll) & PA & {$[32,33]$} \\
\hline $\begin{array}{l}1329 \\
\text { and } 1295\end{array}$ & Asymmetric $\mathrm{SO}_{2}$ stretching & PSf & {$[29,33]$} \\
\hline 1243 & Asymmetric C-O-C stretching & PES, PSf & {$[29,32,33]$} \\
\hline 1151 & Symmetric SO Stretching $_{2}$ strict & PES, PSf & {$[29,33]$} \\
\hline 1106 & $\begin{array}{c}\text { Aliphatic C-C/aromatic hydrogen } \\
\text { bending/rocking }\end{array}$ & PES, PSf & {$[33]$} \\
\hline$\sim 830$ & Para substituted phenyl groups & PSf & {$[32]$} \\
\hline
\end{tabular}




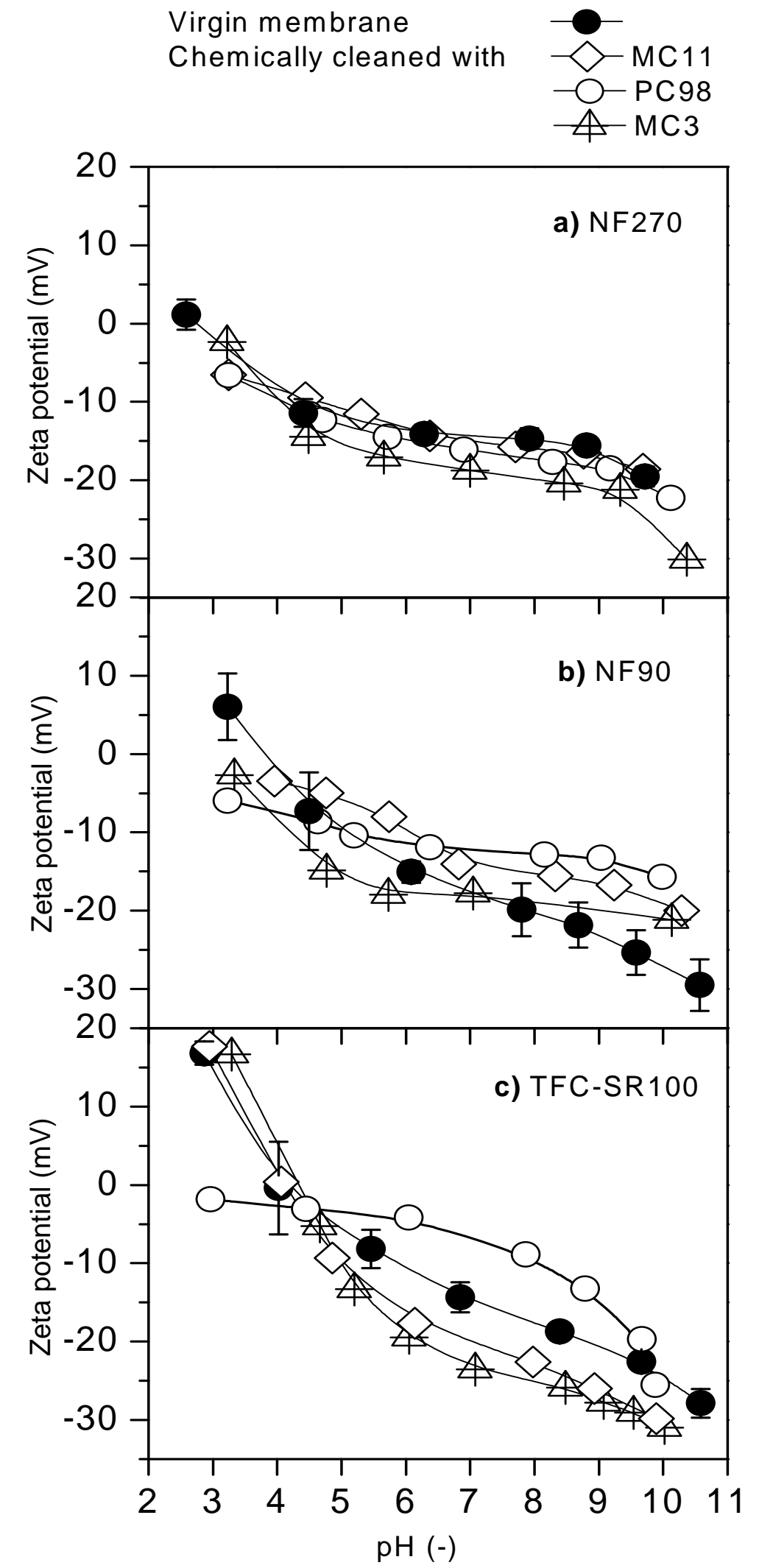

Figure 1 


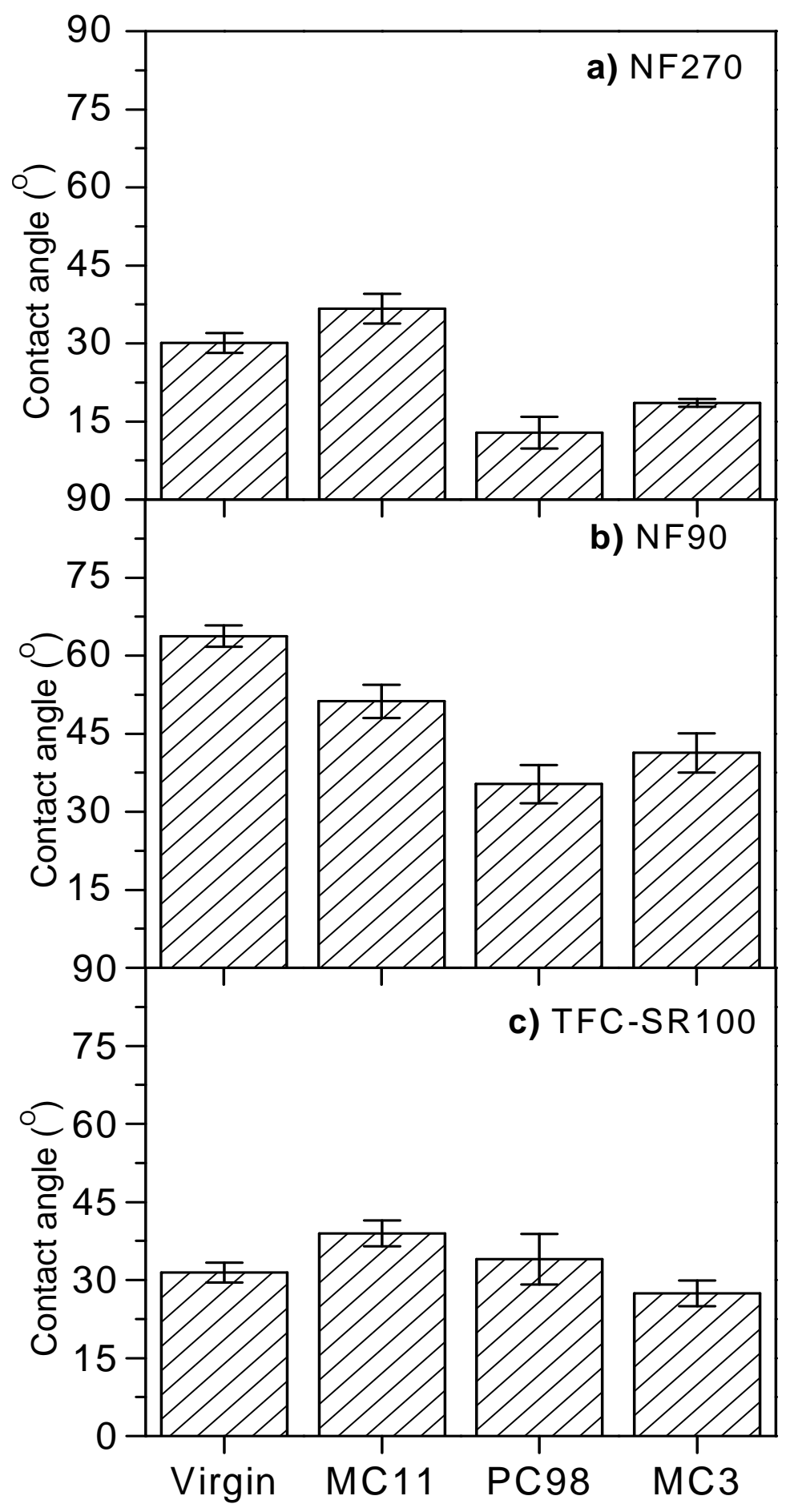

Figure 2 


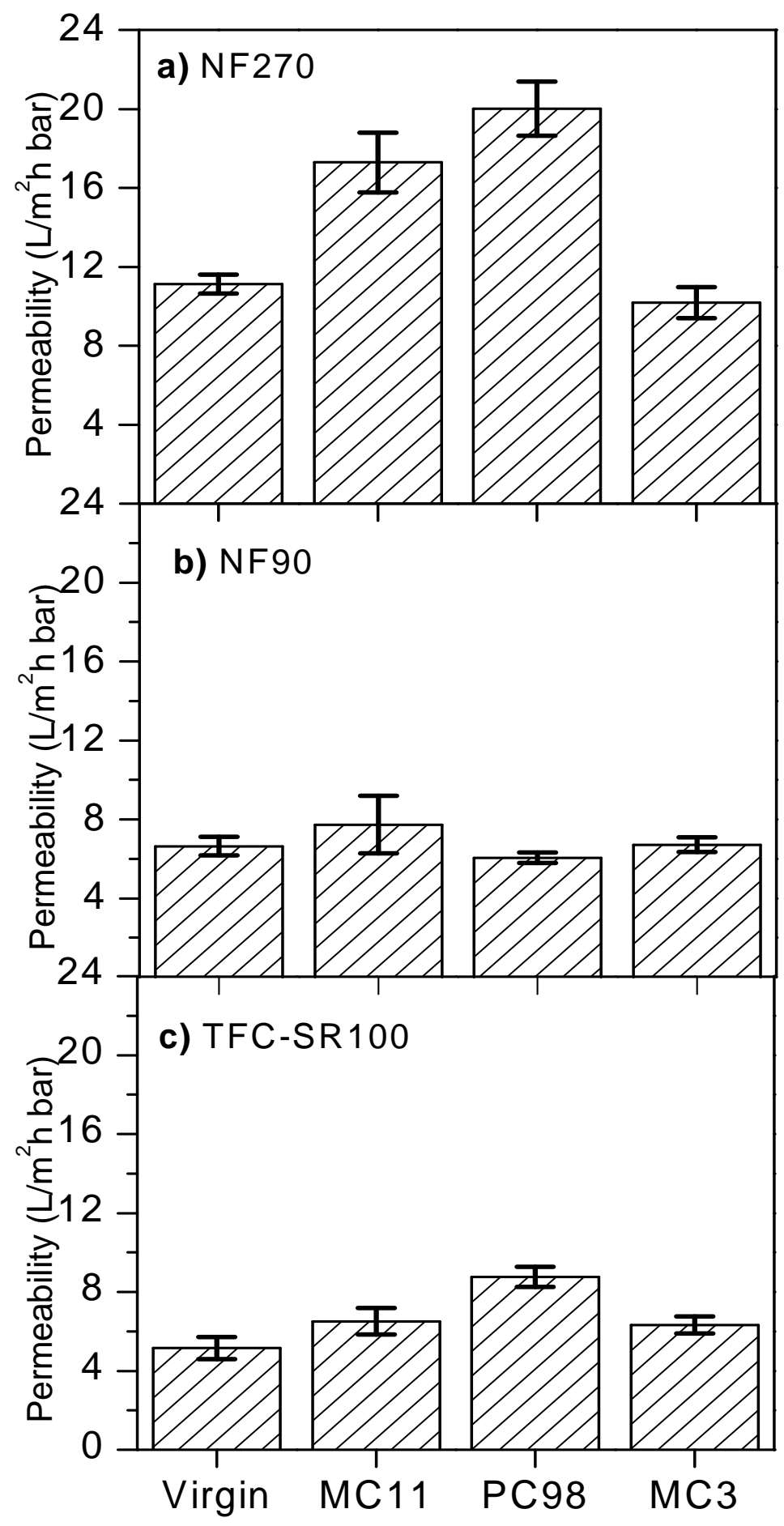

Figure 3 


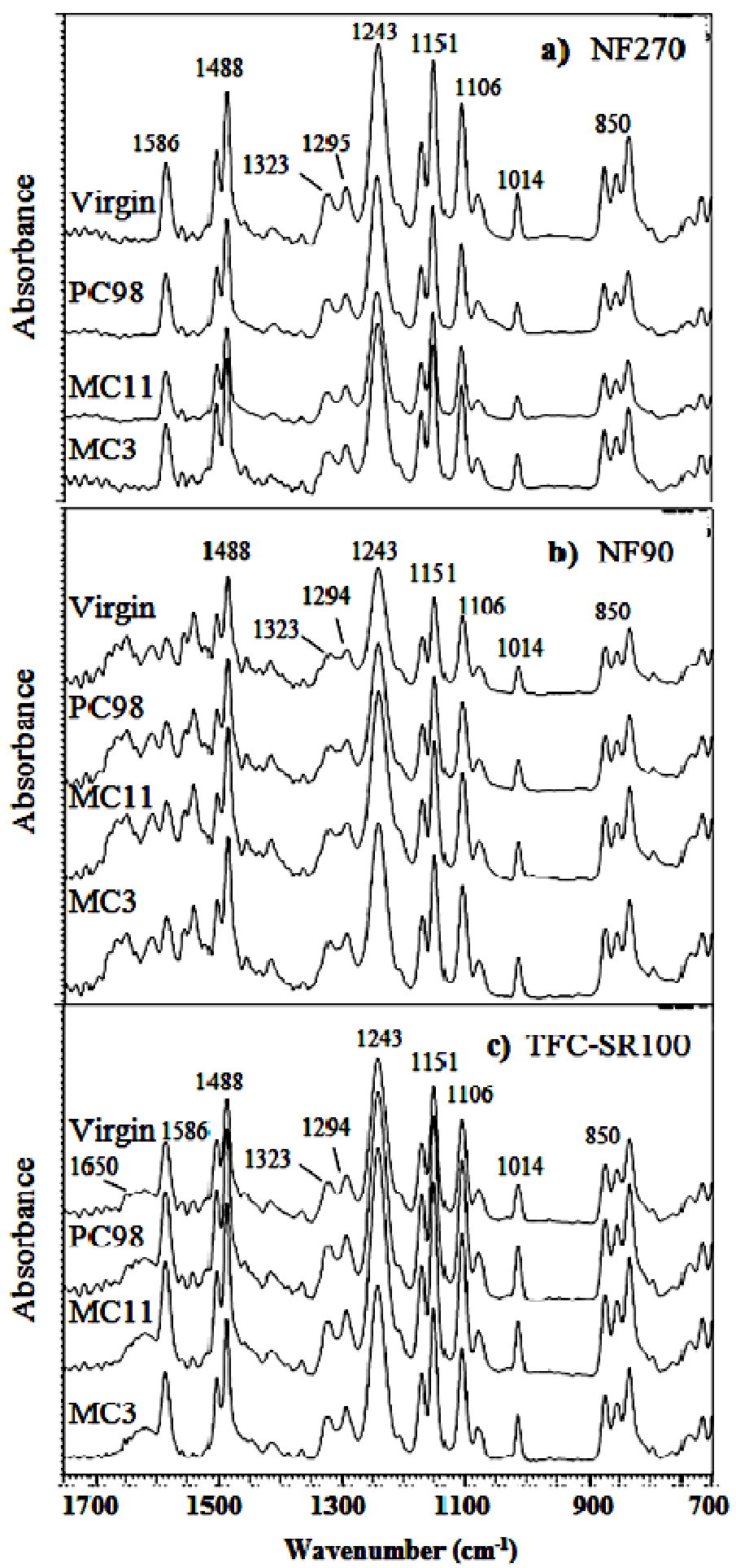

Figure 4 


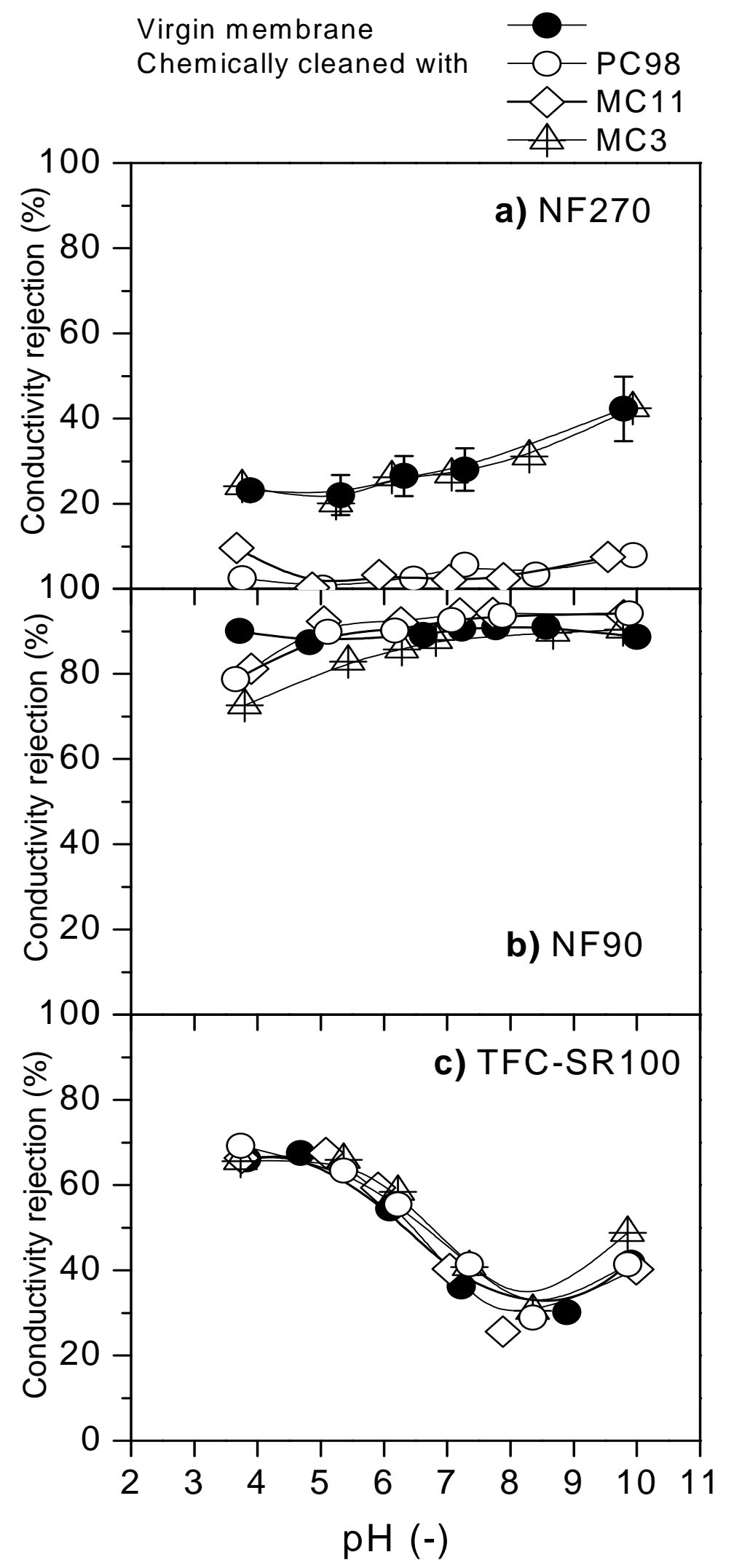

Figure 5 


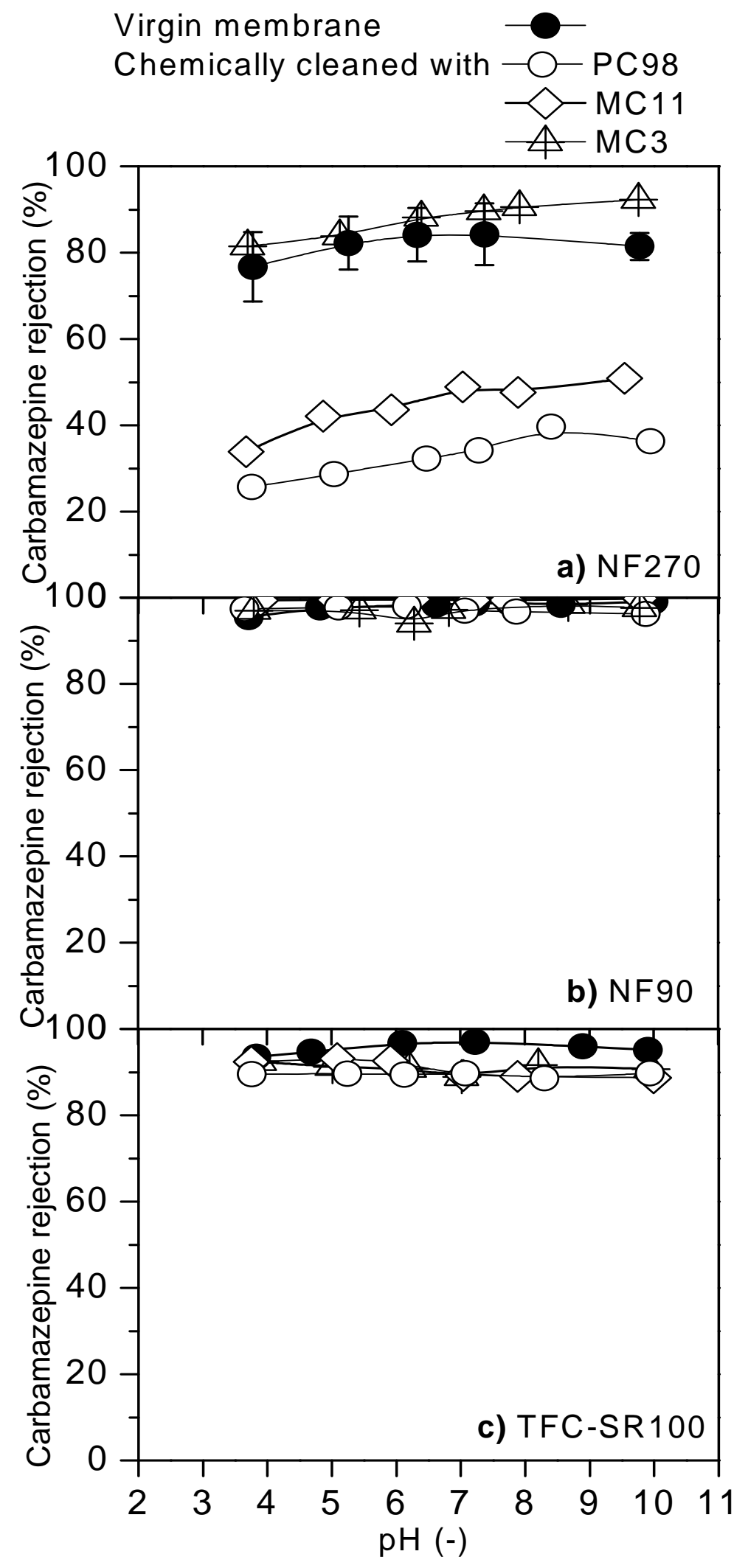

Figure 6 


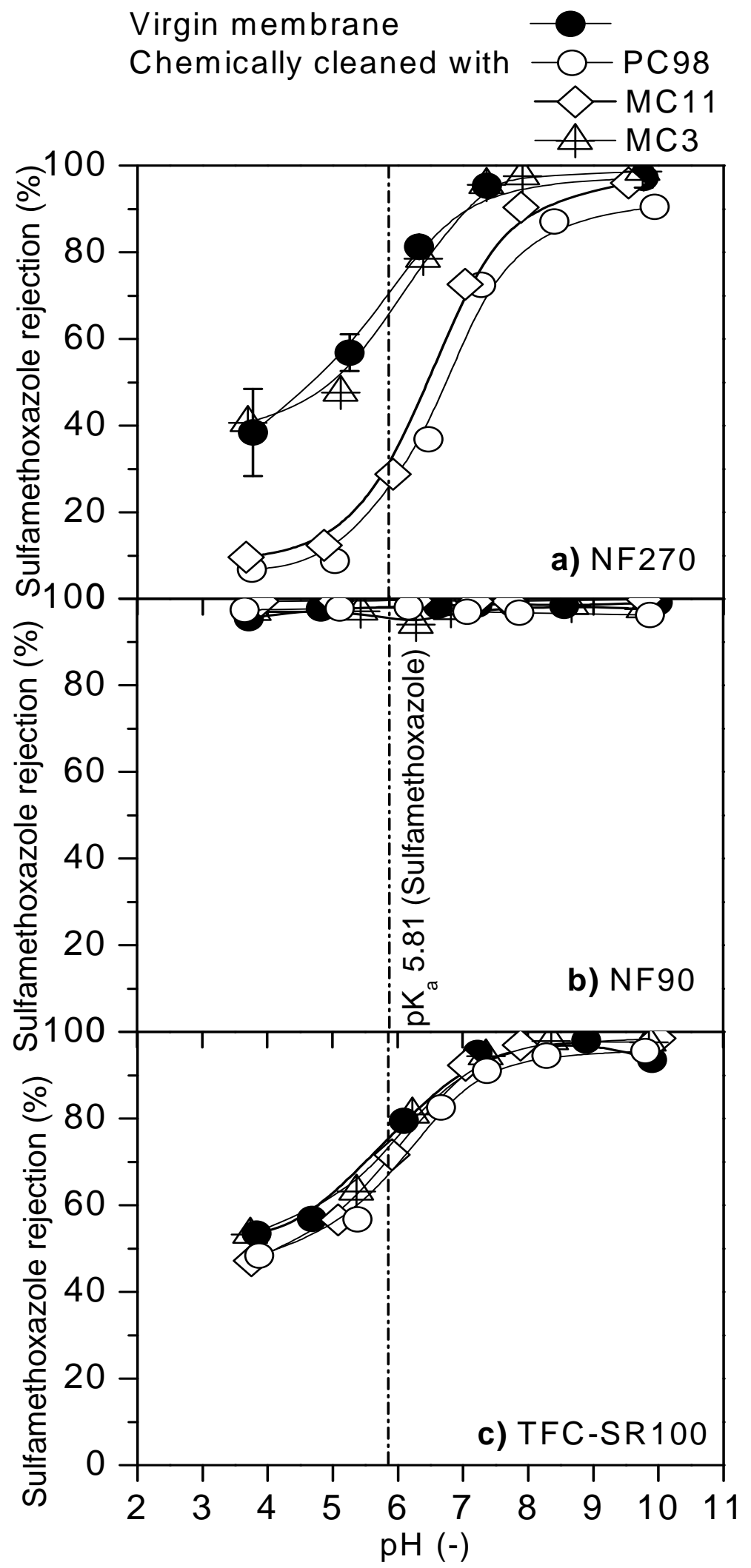

Figure 7 


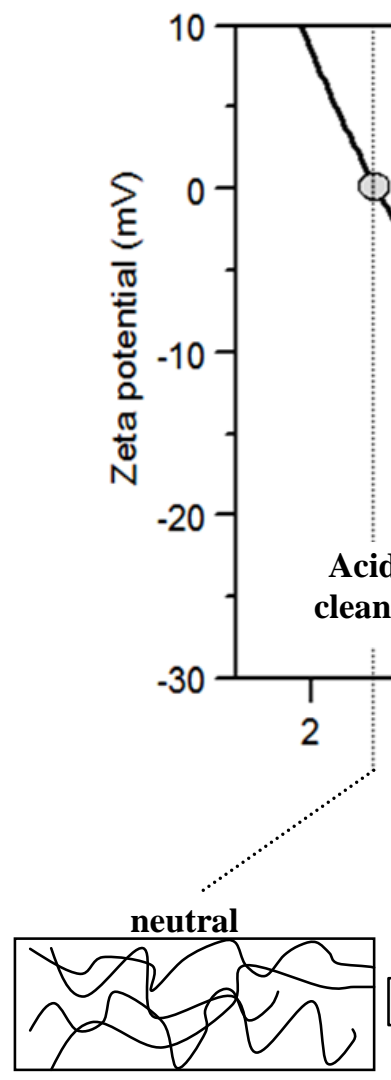

a) Shrinkage of the membrane matrix due to acidic cleaning rendering the membrane neutral

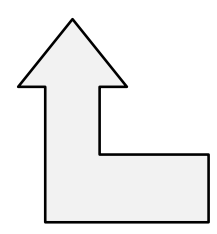

Isoelectric

point

point

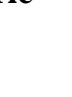

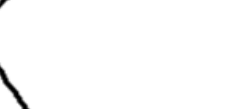

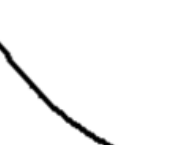

Caustic

cleaning

Acidic

Near neutral pH

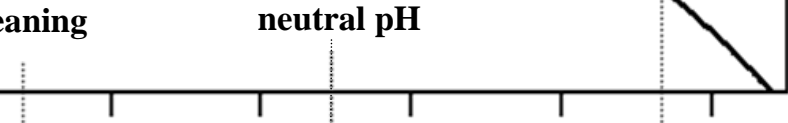

\begin{tabular}{ll|ll|l}
4 & 6 & 8 & 10 & 12
\end{tabular}

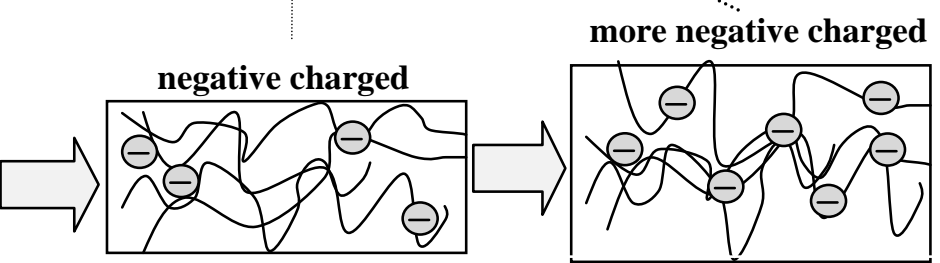

b) Membrane matrix under a normal $\mathrm{pH}$ condition

c) Swelling of the membrane matrix due to caustic cleaning

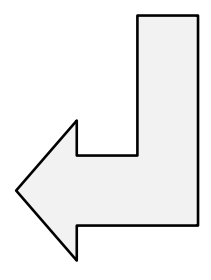

d) Swollen membrane matrix subsequently after caustic cleaning in a normal $\mathrm{pH}$ environment

\section{Figure 8}




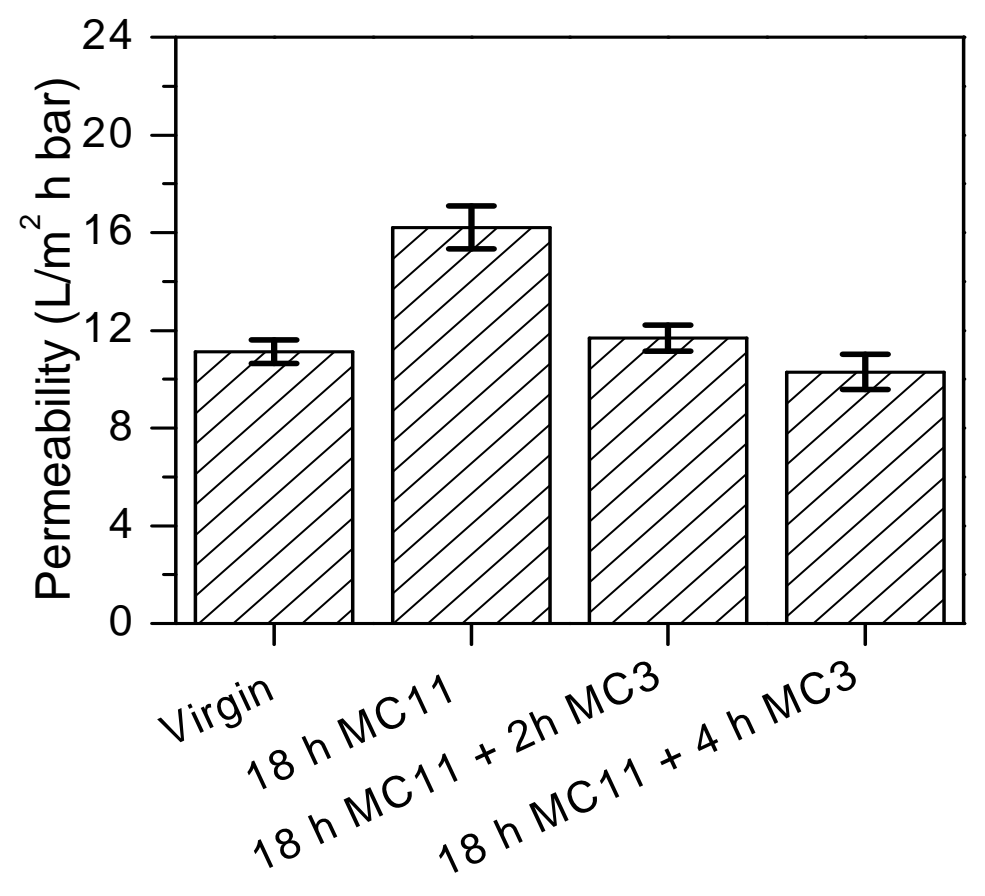

Figure 9 
Virgin membrane

Chemically cleaned with

$\checkmark-M C 11$

$\leadsto 18$ h MC11 + 2 h MC3

-18 h MC11 + 4 h MC3

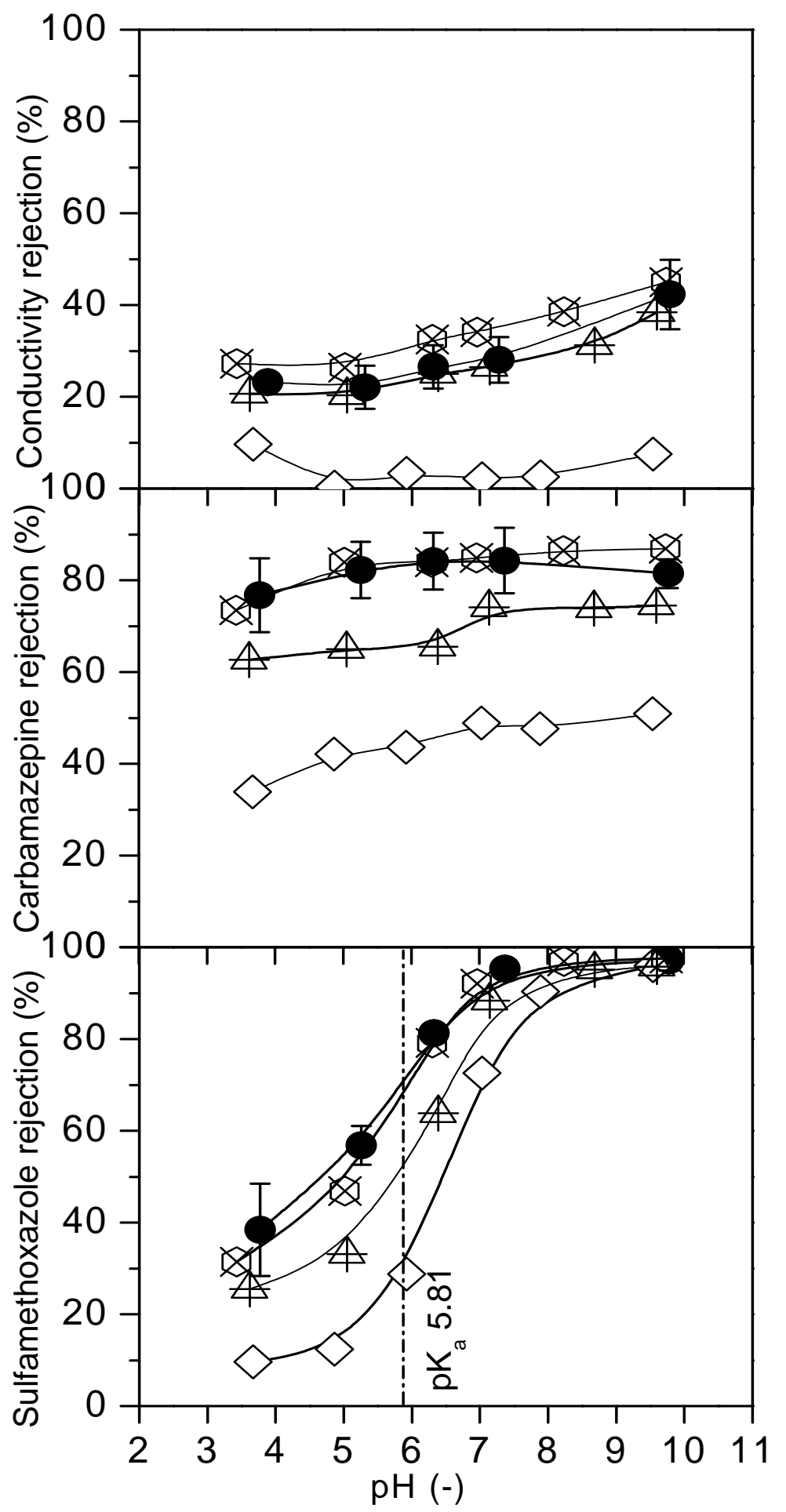

Figure 10 